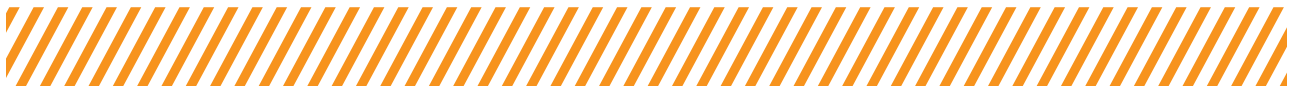

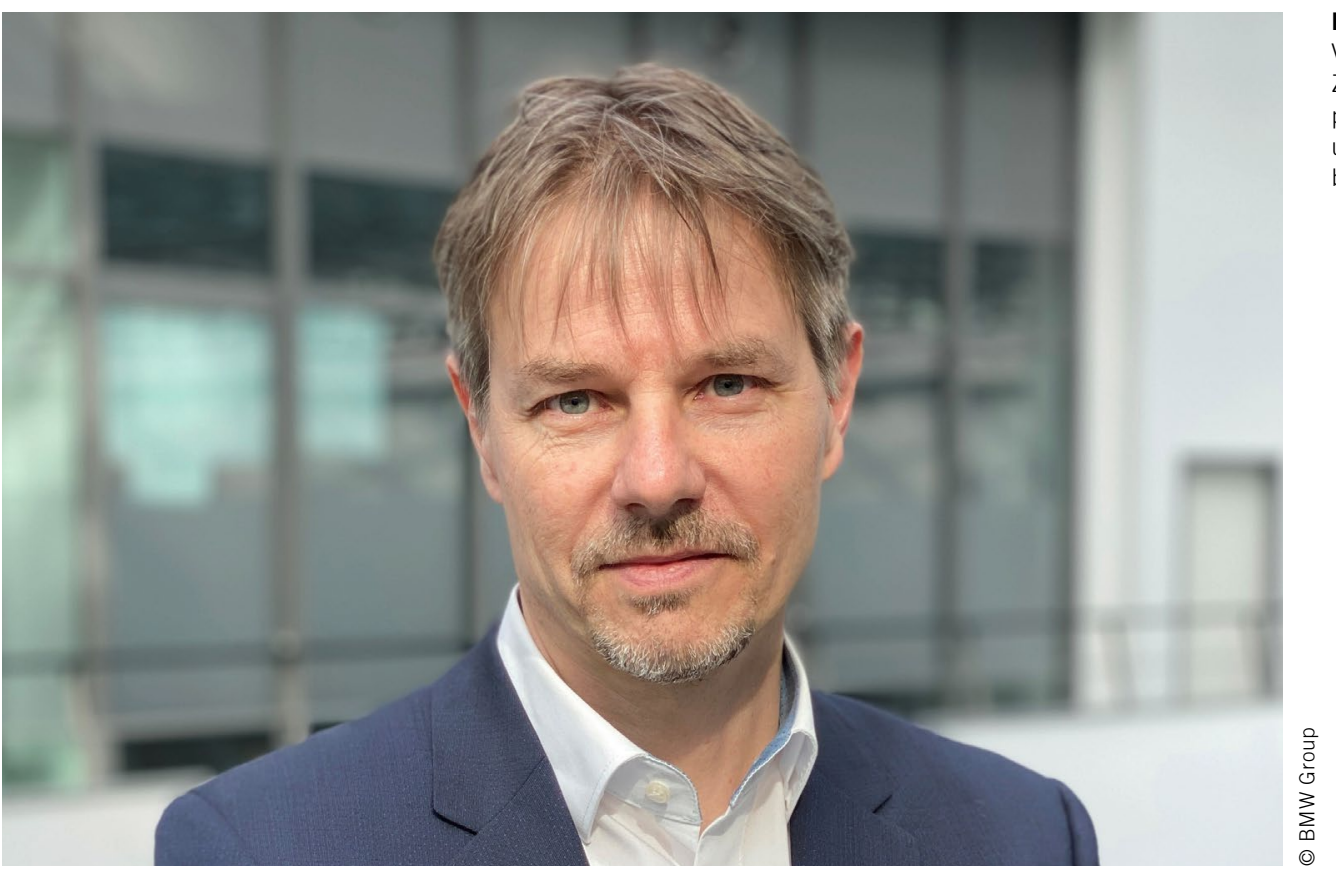

Kai Lars Barbehön Vice President Zentralsteuergeräte, physisches Bordnetz und Energieversorgung bei BMW in München

\section{Nur gut zu sein wird nicht ausreichen!}

Dass die Automobilindustrie im Umbruch ist, ist keine wirkliche Neuigkeit. Man kann höchstens darüber debattieren, welcher Trend sich tagesaktuell als stärkster Veränderungstreiber auszeichnet - ob Elektrifizierung, Automatisierung oder Konnektivität. Gleich aus welcher Perspektive wir es betrachten, gemeinsam ist, dass die Veränderungsgeschwindigkeit uns als Gestalter der Automobilelektronik vor enorme Herausforderungen stellt. Diese Herausforderungen scheinen die Newcomer im Automobilbusiness besser zu bewältigen, als die Automobilhersteller, welche die Mobilität in den vergangenen Jahrzehnten geprägt haben. Um den Anschluss nicht zu verlieren, bedarf es deshalb eines neuen Verständnisses, was Mobilität heute und in Zukunft begehrlich macht: Wir müssen dafür auch bisher geschätzte Werte für die Automobilelektronik wie Robustheit und Qualität durch neue Fähigkeiten wie always fresh/ Update-Fähigkeit erweitern.

Erlebnisse aus der Consumer-Electronics(CE)-Welt bilden hierbei die Referenz. Es geht nicht nur um regelmäßige zyklische Software-Updates Over-the-Air, sondern um ein nahtlos in das digitale Ökosystem des Kunden eingebettetes Fahrzeug als „best managed device“. Nahtlose Zugriffe auf gewohnte digitale Anwendungen direkt aus dem Fahrzeug, temporär buchbare Dienste, Personalisierung und intelligente Assistenten stehen weit oben auf der Wunschliste. Allerdings lassen sich mit heutigen E/E-Architekturen, Entwicklungsprozessen und Aufbauorganisationen Lösungen zu diesen Anforderungen nicht mehr abbilden. Aktuell vorherrschende domänenorien- tierte E/E-Ansätze führen zu nicht mehr beherrschbaren funktionalen Wirkketten. Feingranulare Architekturskalierungen, meist dem Leitgedanken einer zum Verkaufszeitpunkt herstellkostenoptimierten E/E-Konfiguration folgend, resultieren in kundenspezifischen Bordnetzen mit kilometerlangen, aus Tausenden von Einzelmodulen bestehenden Kabelsträngen. Letztlich ist die Grenze der Herstellbarkeit hier bereits erreicht. Dabei liegen die Lösungsansätze eigentlich parat: Hochintegration heute noch verteilter Domänenrechner in hochperformante Integrationsplattformen mit Rechenperformances, die bislang nur aus der CE-Welt bekannt sind, zonale physische Bordnetzarchitekturen mit automatisiert fertigbaren Stufenleitungssätzen in dedizierten Bereichen an sogenannten Zonenmodulen kontaktiert sowie intelligente Energiebordnetze mit über E-Fuses funktional schaltbaren Strängen, die den Anspruch an höchst energieeffizientes Energiemanagement und sichere Energieversorgung Rechnung tragen. Die Kurskorrektur bedarf jedoch eines Umdenkens in der Organisation und den betriebswirtschaftlichen Steuerungsansätzen, denn die Steuerung auf Berichtstypen stößt mit den neuen Ansätzen an ihre Grenzen. Hochintegration und damit Hardwarevorhalte, Software-Updates sowie die Fähigkeit zur Buchung von Services eröffnen digitale Nachverkaufsmöglichkeiten, die in Wirtschaftlichkeitsbetrachtungen zu berücksichtigen sind.

Als neues Mitglied im Beirat der ATZelektronik freue ich mich darauf, diesen spannenden Weg der Veränderung in der Automobilelektronik gemeinsam mit Ihnen gestalten zu können. 